\title{
SUSTENTABILIDADE DAS CIDADES: ASPECTOS CONCEITUAIS ${ }^{1}$ \\ Sustainability of cities: conceptual aspects
}

\author{
Maria Luiza Malucelli ARAÚJO²
}

\section{RESUMO}

A tentativa de conciliar a proteção da natureza e a sua utilização é considerada como um desafio à sustentabilidade no contexto atual. Há diferentes critérios e conceitos a serem utilizados para que o desafio ambiental se torne uma oportunidade, e não um fator gerador da insustentabilidade das cidades. Para se atingir os ideais de sustentabilidade urbana, devem ser conjugados os interesses sociais e ambientais, baseados em políticas integradas, além de se considerar que, face à multiplicidade dos agentes envolvidos, não poderão ser deixadas de lado questões sociais, como saúde, emprego e moradia. A questão que se coloca é se é possível falar em termos de cidades sustentáveis, ou se a sustentabilidade extrapola os limites das cidades, cujas relações sociais e espaciais já ultrapassaram a escala municipal.

Palavras-chave:

Sustentabilidade urbana; urbanização; política urbana.

\begin{abstract}
The attempt to conciliate nature protection and its use is considered as a challenge to sustainability in the current context. There are different criteria and concepts to be applied so the environmental challenge becomes an opportunity rather than a factor generating unsustainability within cities. In order to achieve the ideals of urban sustainability, social and environmental concerns must be conjugated, based on integrated policies. Furthermore, it must be considered that due to the multiplicity of the involved agents, social issues such as health, employment and housing cannot be set aside. The question that is placed than is if it is possible to speak in terms of sustainable cities, or if sustainability surpasses the boundaries of cities, whose social and space relations already have exceeded the municipal scale.
\end{abstract}

\section{Key-words:}

Urban sustainability; urbanization; urban policy.

${ }^{1}$ Este texto foi elaborado a partir do capítulo I da dissertação A Ocupação Urbana em Almirante Tamandaré: um desafio à sustentabilidade, defendida em 2005 no Programa de Pós-Graduação em Geografia da Universidade Federal do Paraná sob orientação da professora Dra. Olga Lúcia Castreghini de Freitas Firkowski.

2 Arquiteta Urbanista, especialista em Arquitetura Bioambiental pela Pontifícia Universidade Católica do Paraná (PUC-PR); especialista em Gestão Técnica do Meio Urbano pela PUC-PR; mestre em Geografia pelo Programa de Pós-Graduação em Geografia pela UFPR. Arquiteta da Comec. E-mail: maluaraujo@onda.com.br 


\section{INTRODUÇÃO}

O processo de urbanização é característico da civilização contemporânea. No Brasil, esse processo foi muito marcante nos últimos cinqüenta anos, quando se transformou de um país rural para urbano.

Segundo Santos, "alcançamos, neste século, a urbanização da sociedade e a urbanização do território, depois de longo período de urbanização social e territorialmente seletiva." (SANTOS, 1996, p. 9).

As cidades contemporâneas são marcadas pelo fenômeno urbano, que produz espaços de privilégio e exclusão, de especulação e de inovação, com transformações ambientais que provocam incerteza quanto ao futuro das cidades.

No início do ano 2000 , a taxa de urbanização brasileira representava $82 \%$ do total de 169 milhões de habitantes, sendo que nas aglomerações metropolitanas os problemas urbanos se apresentavam de maneira mais evidente.

A complexidade que envolve as relações metropolitanas, muitas vezes contraditórias, com focos de tensões sociais e políticas, tem se constituído no maior dilema a ser enfrentado pelas administrações municipais e pelos governos estadual e federal.

A partir desse entendimento e, adotando-se os pressupostos de que o caminho da urbanização é inexorável, e de que o processo de urbanização aponta para a contradição entre preservação, degradação e transformação do espaço, utilizaremos o conceito de sustentabilidade, aplicado no âmbito das cidades. Nesse sentido, o objetivo deste trabalho é fazer um balanço da discussão sobre a sustentabilidade, aplicada ao urbano.

A cidade deve ser vista como uma totalidade, não podendo ser tratada nem compreendida de modo fragmentado, posto que a totalidade se apresenta como um fenômeno integrado. Esse é o entendimento de Alva, o qual enfatiza que a cidade deve ser entendida de forma holística, a partir da perspectiva do meio ambiente, numa concepção de desenvolvimento sustentável, como forma de alterar a degradação ambiental que atinge a maioria das cidades do planeta (ALVA, 1997).

No entanto, considera-se que a sustentabilidade urbana extrapola os limites político-administrativos das cidades e essa afirmação fica evidenciada nas aglomerações urbanas metropolitanas, onde estão presentes e em constante modificação extensas manchas urbanas, articuladas através de complexas interações e fluxos.

A idéia de sustentabilidade permeia, de maneira geral na última década, as discussões que envolvem o desenvolvimento e, de forma muito polêmica, a questão da cidade como espaço do homem.

\section{SUSTENTABILIDADE: UM CONCEITO DINÂMICO}

A introdução da noção de desenvolvimento sustentável na pauta de discussões sobre o meio ambiente iniciou-se no debate de Estocolmo, em 1972, e consolidou-se vinte anos depois, no Rio de Janeiro.

Essa discussão ganhou relevância a partir do Fórum Global de ONGs, que ocorreu em paralelo à Conferência das Nações Unidas para o Meio Ambiente e Desenvolvimento (ECO 92), quando ficou explícito que a questão ambiental era também uma questão urbana.

Até hoje não há consenso sobre a conceituação de sustentabilidade, ora ela é considerada como um conceito em evolução, ora como um conceito em construção, ou como algo que não é possível definir precisamente ou dimensionar, pois se trata de uma noção que pode ser utilizada para defender diferentes posições e idéias.

Apesar da intensa gama de interpretações encontradas na literatura, a definição mais aceita no âmbito internacional foi a da Comissão Mundial sobre Meio Ambiente e Desenvolvimento, o Relatório Brundtland Nosso Futuro Comum (1991, p. 46), segundo o qual "o desenvolvimento sustentável é aquele que atende às necessidades do presente sem comprometer a possibilidade de as gerações futuras atenderem as suas próprias necessidades".

Esse Relatório possui dois conceitos-chave que são: as necessidades dos pobres do mundo, consideradas como prioritárias; e a noção das limitações que o nível da tecnologia e da organização social impõem ao meio ambiente (COMISSÃO MUNDIAL SOBRE MEIO AMBIENTE E DESENVOLVIMENTO, 1991, p.46).

Mas essa definição não é garantia para um desenvolvimento sustentável, pois, como assevera Guimarães, "em situações de extrema pobreza, o ser humano empobrecido, marginalizado ou excluído social e economicamente em âmbito nacional não tem como assumir qualquer compromisso para evitar a degradação ambiental, se é que a própria sociedade não é capaz de impedir sua deterioração enquanto pessoa." (GUIMARÃES, 1991, p. 24).

Assim, em regiões onde há problemas de desigualdade e de exclusão social, a questão social associada à sustentabilidade requer a implantação de políticas públicas que atendam a necessidades básicas como educação, saúde e habitação em condições dignas.

$\mathrm{O}$ crescimento urbano e o desenvolvimento econômico também geram alterações no meio físico, e um dos recursos mais impactados é a água, a qual deve ser protegida visando à manutenção da integridade global do ecossistema.

O conceito de ecodesenvolvimento foi utilizado pela primeira vez por Maurice Strong, em 1973, visando 
à caracterização de uma concepção alternativa de política de desenvolvimento. Os princípios básicos foram elaborados por Ignacy Sachs em 1993, que estabeleceu a existência de cinco dimensões do ecodesenvolvimento: i) sustentabilidade social; ii) sustentabilidade econômica; iii) sustentabilidade ecológica; iv) sustentabilidade espacial; e v) sustentabilidade cultural. Através desta leitura, Sachs explicita a necessidade de compatibilização da melhoria dos níveis de qualidade de vida e da preservação ambiental. (JACOBI, 1999, p. 175-176).

Assim, a sustentabilidade é considerada por Sachs (1996) como um conceito dinâmico. Ele considera também que devem ser levadas em conta as necessidades das pessoas em um cenário em que há constantes expansões e mudanças.

Dentre as dimensões estabelecidas por Sachs, há duas que se destacam, por serem as mais difíceis de ser alcançadas face à perspectiva apontada pela etapa atual de desenvolvimento do capitalismo, que são a sustentabilidade social e a cultural. (SACHS, 1996, p. 474). prevê

Sachs esclarece que a sustentabilidade social

o estabelecimento de um processo de desenvolvimento que conduza a um padrão estável de crescimento, com uma distribuição eqüitativa da renda e dos ativos, assegurando uma melhoria substancial dos direitos das grandes massas da população e uma redução das atuais diferenças entre os níveis de vida daqueles que têm e daqueles que não têm. (SACHS,1996, p. 474).

A sustentabilidade cultural para Sachs constituise na "dimensão mais difícil de ser concretizada, na medida em que implica que o processo de modernização deveria ter raízes endógenas, buscando a mudança em sintonia com a continuidade cultural vigente em contextos específicos." (SACHS, 1996, p. 475).

A tentativa de conciliar a proteção da natureza e a sua utilização é considerada como um desafio à sustentabilidade no contexto atual. Segundo Sachs, o desafio é:

como conservar escolhendo-se estratégias corretas de desenvolvimento em vez de simplesmente multiplicarem-se reservas supostamente invioláveis? Como planejar a sustentabilidade múltipla da Terra e dos recursos renováveis? Como desenhar uma estratégia diversificada de ocupação da Terra, na qual as reservas restritas e as reservas da biosfera tenham seu lugar nas normas estabelecidas para o território a ser utilizado para usos produtivos? SACHS (2002, p.32).
Autor considera ainda que os usos relacionados à produção não têm como pressuposto a geração de prejuízos ambientais, a partir do momento em que se tenha consciência de que todas as nossas atividades econômicas estão intimamente ligadas ao ambiente natural. (SACHS, 2002, p. 32).

Destaca como três os pilares do desenvolvimento sustentável: os critérios de relevância social, prudência ecológica e viabilidade econômica.

Considera que os países tropicais, ao efetuarem o aproveitamento racional da natureza, contribuirão para um gerenciamento global inteligente da biosfera. Assim, entende que o Brasil e outros países tropicais têm excelentes condições de se tornar exportadores da sustentabilidade, a partir da transformação do desafio ambiental em uma oportunidade. (SACHS, 2002, p. 3542).

O Autor entende que, independentemente da denominação de ecodesenvolvimento ou desenvolvimento sustentável, a abordagem que se fundamenta na harmonização de objetivos sociais, ambientais e econômicos permanece inalterada desde o encontro de Estocolmo até as conferências do Rio de Janeiro, e acredita que ainda é válida - e continua recomendando a utilização dos oito critérios distintos de sustentabilidade parcial, acima descritos. (SACHS, 2002, p. 54).

O termo sustentabilidade muitas vezes é empregado para expressar a sustentabilidade ambiental, mas este conceito tem outras dimensões, das quais a social é a mais importante, por ser a própria finalidade do desenvolvimento. (SACHS, 2002, p. 71).

Sob o ponto de vista ecológico, destacamos o conceito de sustentabilidade no sentido que é muito utilizado atualmente, isto é, como:

a capacidade que tem um ecossistema de atender às necessidades das populações que nele vivem - ou como um conceito político que limita o crescimento em função da dotação de recursos naturais, da tecnologia aplicada no uso desses recursos e do nível efetivo de bem-estar da coletividade. (ALVA, 1997, p. 60-61).

Há posições mais radicais que não aceitam a possibilidade de conciliar a proteção do meio ambiente com a ocupação humana e que consideram o processo de urbanização irreversível.

O processo de urbanização representa um sério desafio para o pensamento que se articula em torno do conceito de desenvolvimento sustentável. Este se entenderá, a partir do exposto, não como um estado final, ainda que fosse de "equilíbrio ecológico", mas como um processo: uma transição para graus de racionalidade crescente, regida por um projeto cultural que transcen- 
de os âmbitos biofísico, econômico ou político, ainda que desenvolva a todos eles.

Tudela (1997) apresenta uma visão mais crítica em relação à urbanização, na qual, aparentemente, cidade e meio ambiente não podem ser conjugados - ou talvez até possam, mas segundo uma teoria que não consegue estabelecer qual é o critério que define o limite da sustentabilidade urbana. Segundo o autor:

Como pode um pensamento que defende a necessidade de conservar os recursos naturais e de manter aberto o leque de opções das futuras gerações definir e assimilar a mais radical e irreversível das transformações antrópicas, que é a conversão de uma paisagem natural em cidade? (TUDELA, 1997, p.137).

Alva considera que "a sustentabilidade coloca novas formas de relação entre o desenvolvimento socioeconômico, o crescimento urbano e a qualidade ambiental. A definição desta é diferente em cada aglomeração, não obstante a presença de situações comuns que aproximam entre si as metrópoles latino-americanas e, até certo ponto, as aproximam também às da Ásia e da África". (ALVA, 1997, p. 145).

No que tange à questão do território, a sustentabilidade está, conforme a visão de Sachs, vinculada a uma distribuição territorial equilibrada de assentamentos humanos e atividades, produto de configurações urbanas e rurais balanceadas. (SACHS, 2002, p. 71).

Tomando como base a questão territorial e as ações humanas que podem interferir no espaço urbano, entende-se que há diferentes critérios e conceitos a serem utilizados para que o desafio ambiental se torne uma oportunidade, e não um fator gerador da insustentabilidade das cidades.

Sob um ponto de vista mais abrangente, destaca-se uma evolução conceitual, que vem da ECO 92. Os debates que ocorreram no evento resultaram em mudanças nas concepções relativas ao meio ambiente, gerando novas maneiras de se conceber os problemas ambientais, nos quais se destaca a questão social.

Mendonça entende que a dimensão social desses problemas:

possibilitou o emprego da terminologia socioambiental, e este termo não explicita somente a perspectiva de enfatizar o envolvimento da sociedade como elemento processual, mas é também decorrente da busca de cientistas naturais a preceitos filosóficos e da ciência social para compreender a realidade numa abordagem inovadora. (MENDONÇA, 2002, p.127).

Sobre as diferentes opiniões quanto à definição de sustentabilidade, Acselrad entende que "a suposta imprecisão do conceito de sustentabilidade sugere que não há ainda hegemonia estabelecida entre os diferentes discursos". (ACSELRAD, 2001, p. 28).

Acselrad considera que a noção de sustentabilidade está submetida a efeitos sociais que se deseja produzir, e favorece o discurso que pretende transformar uma realidade objetiva. E ainda, que "o futuro das cidades dependerá em grande parte dos conceitos constituintes do projeto de futuro dos agentes relevantes do espaço urbano." (ACSELRAD, 2001, p. 28-30).

Este parece ser o ponto-chave da sustentabilidade: qual o projeto de futuro dos agentes relevantes do espaço urbano?

Sobre isso também se pode questionar: quem seriam os agentes relevantes do espaço urbano? Conforme definição de Corrêa (1995), seriam aqueles agentes que produzem a cidade capitalista, como os grandes industriais, os proprietários fundiários, os promotores imobiliários, o Estado e os grupos sociais excluídos. Há uma categoria muito importante, que abrange os grupos sociais excluídos, que é a comunidade local. Essa categoria, apesar de todos os discursos, ainda é a menos ouvida, e parece ainda ser o agente menos relevante. No entanto, é a comunidade que deve participar dos processos de decisão, a fim de articular e implantar o seu conceito de futuro, o seu interesse comum.

\section{SUSTENTABILIDADE: UM CONCEITO APLICÁVEL?}

Para um aprofundamento na análise da sustentabilidade das cidades, é necessária uma discussão do que afinal vem a ser "sustentabilidade urbana". Podemos considerá-la como um ideal a ser perseguido por uma cidade que deseja ser sustentável? Ou o conceito pode ser aplicado também em espaços urbanos integrados em uma aglomeração urbana metropolitana ou em uma região?

A adoção do conceito de sustentabilidade e a sua aplicação no âmbito das cidades requer uma interação de mão dupla entre o debate ambiental e as questões urbanas. Há uma preocupação crescente com a temporalidade das cidades, com a concentração populacional nas metrópoles, com os conflitos entre a ocupação urbana e as redes de abastecimento de água etc. Há uma incerteza quanto ao futuro, e o debate tem início com a busca dos futuros idealizados que se deseja tornar realidade (ACSELRAD, 2001, p. 21).

Concorda-se com o pensamento de Acselrad, quando aponta que: "O que caracteriza as cidades contemporâneas, sob os efeitos da globalização, é justamente a profunda desigualdade social na exposição aos riscos ambientais." (ACSELRAD, 2001, p. 23). 
Esse é um assunto que vem causando muitas controvérsias, além de diversos questionamentos, dentre os quais se destaca um efetuado por Acselrad: "Como pensar e construir, no presente, o futuro desejável, democrático e justo das cidades?". O autor entende que "trata-se de buscar subordinar a 'economia do ambiente urbano' aos princípios de uma justiça ambiental aplicada às cidades". (ACSELRAD, 2001, p. 24).

Nesse sentido, manifesta seu entendimento de como deve ser a aplicação efetiva do conceito de sustentabilidade no âmbito das cidades.

A análise do discurso das cidades que se apresentam como candidatas a protagonizar a sustentabilidade urbana sugere que as mesmas pretendem inserir-se em uma continuidade temporal e espacial através dos procedimentos de descentralização (pela legitimação do não-humano, das gerações futuras, dos parceiros inertes ou virtuais), de restauração (pela reciclagem de recursos naturais, bairros, rios, ofícios, saberes, imagens e instituições) e de interação dos fenômenos urbanos (o ar da cidade com o ar do planeta, a ocupação do solo com o abastecimento d'água, atividades presentes e valores herdados, agências de urbanismo com instâncias de concertação). A inclusão das periferias via descentralização, da memória via restauração e dos atores sociais via interação constituem, assim, procedimentos discursivos de expansão simbólica da base de legitimação das políticas urbanas. A busca de um consenso urbano de tal forma ampliado espacial e temporalmente, legitimado nos propósitos do equilíbrio biosférico e da justiça intergeracional, se justifica, por certo, pela necessidade de prevenção dos riscos de ruptura sociopolítica em cidades crescentemente fragmentadas pelos processos de globalização e acumulação flexível. (ACSELRAD, 2001, p. 51).

A reflexão sobre a sustentabilidade do meio urbano, em um contexto municipal ou, de maneira mais complexa, num contexto regional deve partir do pressuposto básico de que o espaço urbano não pode ser simplesmente considerado um espaço insustentável. O que deve ser analisado é que não há como desvincular a questão ambiental da questão urbana em ambientes já ocupados, ou que serão ocupados.

Nos dias atuais, onde a sociedade é cada vez mais urbana, é uma necessidade premente tratar de forma integrada as questões sociais e urbanas.

Sobre esse assunto, Steinberg (2001, p. 1341) considera que não se pode analisar o meio ambiente urbano com olhares de ontem, quando essa consciência sequer existia, e também não é possível separar o urbano do ambiental. Entende que o espaço urbano e o meio ambiente não podem ser considerados como um substrato do meio ambiente urbano, posto que meio ambiente urbano é uma outra "coisa", que necessita ser observada através de um novo olhar.

Para que esse novo olhar seja construído, Steinberg (2001) conclui que há três conceitos e noções que devem ser analisados para que se alcance a idéia de sustentabilidade urbana: i) ambiente-meio ambiente; ii) desenvolvimento sustentável-sustentabilidade; e iii) território-urbanização.

Assim, constata-se que há muitas versões sobre o assunto, que a sustentabilidade urbana é um conceito-chave no debate atual, que é essencialmente espacial, e que contém contradições que se potencializam no espaço urbano.

Na perspectiva do presente trabalho, entende-se que, apesar de uma noção polêmica, nela estão presentes alguns elementos capazes de contribuir para a reflexão sobre o conflito entre a necessidade de ocupação de áreas na cidade e as questões ambientais.

Assim, para se atingir os ideais de sustentabilidade urbana, devem ser conjugados os interesses sociais e ambientais, baseados em políticas integradas, além de se considerar que, face a multiplicidade de agentes envolvidos, não poderão ser deixadas de lado questões sociais, como a saúde, o emprego e a moradia.

A questão que se coloca é se afinal é possível falar em termos de cidades sustentáveis, ou se a sustentabilidade extrapola os limites das cidades, como é o caso das cidades integrantes de aglomerados urbanos.

\section{CIDADES SUSTENTÁVEIS E POLÍTICA URBANA}

Após a promulgação da Constituição Federal de 1988, o texto constitucional deu ênfase à política urbana. E com a aprovação do Estatuto da Cidade em 2001, em vigor desde 10 de outubro de 2001, surgiu a exigência de elaboração de Plano Diretor para cidades: i) com mais de vinte mil habitantes; ii) integrantes de regiões metropolitanas e aglomerações urbanas; iii) onde o Poder Público municipal pretenda utilizar os instrumentos previstos no parágrafo $4^{\circ}$ do artigo 182 na Constituição Federal; iv) integrantes de áreas de especial interesse turístico; v) inseridas na área de influência de empreendimentos ou atividades com significativo impacto ambiental de âmbito regional ou nacional.

O Estatuto da Cidade vem regulamentar os artigos 182 e 183 da Constituição Federal - e com isso possibilitar a instituição de instrumentos efetivos na gestão da ocupação do solo urbano, operacionalizando as disposições constitucionais, revestindo-se de vital importância para a modernização do processo de planejamento e gestão das cidades brasileiras. 
Com a inclusão obrigatória da participação da sociedade no processo de gestão, começa-se a vislumbrar uma nova época, em que as questões sociais/urbanas passarão a ser tratadas de uma maneira especial, em que a discussão entre os diversos atores da sociedade tende a ser cada vez mais enriquecedora e construtiva, na busca de um ambiente sustentável e socialmente justo.

A Lei do Estatuto da Cidade, segundo Davidovich, acrescentou aspectos positivos à concepção do local, introduzindo práticas de cidadania e redução das desigualdades sociais. No entanto, ele pondera que as expectativas de integração entre municípios metropolitanos são prejudicadas pelo "neolocalismo", que apregoa uma gestão empresarial para a cidade, com incentivo para a "guerra fiscal" entre lugares, visando a competitividade, mas, com pequena geração de emprego, de serviços e infraestrutura para a população. (DAVIDOVICH, 2003, p. 13).

A Constituição outorgou aos municípios um papel específico na promoção do desenvolvimento econômico e social do País, a partir da descentralização de encargos e recursos e da redistribuição de competências entre os três níveis de governo. Assim, torna-se muito importante a responsabilidade do município na gestão urbana, aqui entendida como prática de governo que envolve planejamento e ação sobre todas as funções e atividades, públicas e privadas, que ocorrem no espaço urbano.

A citada Lei estabeleceu normas de ordem pública e interesse social que regulam o uso da propriedade urbana em prol do bem coletivo, da segurança e do bemestar dos cidadãos, bem como do equilíbrio ambiental, e tem como objetivo ordenar o pleno desenvolvimento das funções sociais da cidade e da propriedade urbana, mediante dezesseis diretrizes gerais, dentre as quais: a garantia do direito à cidades sustentáveis, entendida como o direito à terra urbana, à moradia, ao saneamento ambiental, à infra-estrutura urbana, ao transporte, aos serviços públicos, ao trabalho e ao lazer, para as presentes e futuras gerações.

A partir dessa definição, correlacionam-se princípios que devem ser atendidos visando a sustentabilidade da cidade, sob o aspecto da legislação vigente no âmbito federal, que são traduzidos em qualidade de vida para a população - como o direito a um lote ou a uma moradia urbana, dotada de infra-estrutura básica como água, esgoto, drenagem, coleta de lixo, sistema viário adequado, bem como o direito a um sistema de transporte coletivo eficiente, acesso aos serviços públicos, ao trabalho e aos espaços públicos destinados ao lazer e à recreação.

Todos esses aspectos somados representam o que se considera mais relevante para a sustentabilidade das cidades, a garantia do direito à cidade.
Lefebvre (1991) esclarece que o direito à cidade é o direito à vida urbana, à centralidade renovada, aos locais de encontro e de trocas, aos ritmos de vida e empregos do tempo que permitem o uso pleno e inteiro desses momentos e locais etc.

Segundo o entendimento do autor, a filosofia dá sentido às ciências da realidade social, não se tratando mais de "uma filosofia da cidade e de uma filosofia histórico-social ao lado de uma ciência da cidade." (LEFEBVRE, 1991, p. 138).

Nos dias atuais, a situação teórica é desbloqueada, e ocorre um preenchimento do "abismo que existe entre o total e o parcial ou parcelar, entre o conjunto incerto e os fragmentos certos demais." (LEFEBVRE, 1991, p. 138).

Para Lefebvre "o direito à cidade se manifesta como forma superior dos direitos: direito à liberdade, à individualização na socialização, ao hábitat e ao habitar. $\mathrm{O}$ direito à obra (à atividade participante) e o direito à apropriação (bem distinto do direito à propriedade) estão implicados no direito à cidade." (LEFEBVRE, 1991, p. 116-143).

Assegurar o pleno exercício do direito à cidade é a questão primordial da política urbana que deve ser implantada nas cidades brasileiras, tendo os cidadãos como prioridade.

Então, o aperfeiçoamento dos instrumentos legais, técnicos e financeiros existentes, indispensáveis à implementação de políticas urbanas, deve ser uma preocupação dos governos e, em especial, a elaboração ou revisão da sua legislação urbanística.

No entanto, concorda-se com a visão de Rattner (2001) de que os planos diretores não serão capazes de promover uma melhor distribuição de renda e a reversão do uso da terra como reserva de valor, posto que estas mudanças somente poderão acontecer por meio da mobilização da sociedade. Nesse sentido, segundo Rattner (2001, p.16), o plano diretor "torna-se essencialmente um conjunto de regras que articulam e estruturam a participação de todos os atores sociais, mobilizados e motivados para a tarefa de reabilitação de suas cidades, para o benefício de todos os seus habitantes."

Retomando-se a questão do Estatuto da Cidade, e sendo esse o instrumento que regulamenta as diretrizes gerais da política urbana e que estabelece as normas de ordem pública que regulam o uso da propriedade urbana em prol do interesse coletivo, ele, em princípio, foi elaborado tendo em vista o ordenamento da cidade e da propriedade urbana.

Muitos dos instrumentos previstos pelo Estatuto têm como finalidade a utilização adequada dos espaços vazios da cidade, o que parece sugerir um "modelo de cidade compacta", com vistas ao direito à cidade e a 
otimização da infra-estrutura, evitando assim, a criação de extensas periferias com um grande número de pessoas excluídas, sem as mínimas condições de atendimento por serviços públicos.

Esse parece ser um modelo de cidade sustentável que visa à qualidade de vida de todos os habitantes pela racionalização dos investimentos públicos, a eficiência no uso dos recursos ambientais e a distribuição eqüitativa de todos os benefícios oriundos das políticas públicas.

Analisando o conceito de cidade sustentável contido no Estatuto da Cidade, percebe-se que tal documento considera a propriedade urbana, o direito à terra urbana, sem considerar a propriedade rural. O Estatuto, após delinear claramente o espaço da cidade em seu texto, estabelece que o Plano Diretor deve abranger o município como um todo. Seria mais coerente talvez definir o conceito de município sustentável?

Não nos parece possível uma cidade ser sustentável desconsiderando o restante do município, a sua área rural. Não há como dissociar o urbano e o rural, a cidade e o campo, cada vez mais interdependentes em suas funções de complementaridade.

O modelo de cidade "compacta" dificilmente poderá enquadrar-se no modelo já existente nas grandes cidades, principalmente nas aglomerações urbanas metropolitanas, em que grandes áreas de ocupação passam a configurar uma nova cidade, extrapolando os limites político-administrativos dos municípios.

\section{CONCLUSÃO}

A sustentabilidade, para que atinja o seu objetivo maior, que é o bem-estar da comunidade, deve não somente ser pensada em termos de cidade, mas sob uma nova ótica, a partir de novos conceitos. Assim, ao se pensar em um espaço sustentável, que pode ser uma cidade, um município, um aglomerado ou uma cidaderegião, o que deve ser perseguido é o bem-estar não do indivíduo, mas da comunidade, da população em geral.

Para assegurar a sustentabilidade, é fundamental a busca de alternativas viáveis e adequadas às características e particularidades de cada município. A estratégia de associar-se com outros municípios de uma mesma bacia hidrográfica ou de uma região, e também parcerias com a iniciativa privada podem ser alternativas viáveis na busca de soluções comuns sustentáveis. Nesse sentido, fica evidenciada a importância de que a gestão também possa ser compartilhada em novas escalas que ultrapassem as decisões isoladas municipais.

Nas aglomerações urbanas metropolitanas a sustentabilidade urbana se configura como um desafio a ser vencido, sendo que a sustentabilidade social, por ser a mais importante é considerada uma meta a ser atingida.

É nesse contexto que as questões sociais e ambientais se apresentam mais conflitantes, em que o interesse municipal nem sempre coincide com o regional, em que a produção do espaço urbano muitas vezes não atende à lógica do planejamento.

Considera-se que caso não sejam investidos esforços governamentais a fim de promover o equilíbrio físico, econômico, ambiental e social das aglomerações urbanas metropolitanas, o que se prevê é um futuro agravamento do problema, o que acarretaria um espaço insustentável.

Nesse sentido, e em conformidade com o Estatuto da Cidade, o que se pretende é a busca de cidades verdadeiramente sustentáveis, em que sejam conciliadas a proteção do meio ambiente com os direitos básicos do cidadão.

A garantia de que esse ideal venha a ser alcançado depende do grau de participação da sociedade na discussão dos problemas da cidade, reconhecendo as limitações existentes e buscando soluções conjuntas para o equilíbrio da sociedade urbana/metropolitana.

\section{REFERÊNCIAS}

ACSELRAD, H. Introdução. In: ACSELRAD, H. (Org.). A duração das cidades: sustentabilidade e risco nas políticas urbanas. Rio de Janeiro: DP\&A, 2001. p. 21-25.

Sentidos da sustentabilidade urbana. In: ACSELRAD, H. (Org.). A duração das cidades: sustentabilidade e risco nas políticas urbanas. Rio de Janeiro: DP\&A, 2001. p. 27-55.

ALVA, E. N. Metrópoles in(sustentáveis). Rio de Janeiro: Relume Dumará, 1997. 149 p.
COMISSÃO MUNDIAL SOBRE MEIO AMBIENTE E DESENVOLVIMENTO. Nosso futuro comum. 2. ed. Rio de Janeiro: Fundação Getulio Vargas, 1991. 430 p.

CORRÊA, R. L. O espaço urbano. 3. ed. São Paulo: Ática, 1995. 94 p.

DAVIDOVICH, F. Regiões metropolitanas no Brasil: referências para debate. In: Anais do X Encontro Nacional da ANPUR. Belo Horizonte, 2003, 17 p. 
GUIMARÃES, R. P. O Brasil e o desafio de desenvolvimento sustentável. O desafio do desenvolvimento sustentável: relatório nacional do Brasil para a conferência das nações unidas sobre meio ambiente e desenvolvimento. Brasília, Secretaria de Imprensa da Presidência da República, 1991, p. 13-24.

JACOBI, P. Meio ambiente e sustentabilidade. In: O município no século $X X I$ : cenários e perspectivas. São Paulo: CEPAM. 1999, p.175-183.

LEFEBVRE, H. O direito à cidade. São Paulo: Moraes, 1991.

MENDONÇA, F. A. Geografia socioambiental. In: MENDONÇA, F.; KOZEL, S. (Orgs.). Elementos de epistemologia da geografia contemporânea. Curitiba: UFPR, 2002. p. 121-144.

RATTNER, H. Prefácio. ACSELRAD, H. (Org.). A duração das cidades: sustentabilidade e risco nas políticas urbanas. Rio de Janeiro: DP\&A, 2001. p. 9-19.

SACHS, I. Desenvolvimento sustentável, bio-industrialização descentralizada e novas configurações rural-urbanas: os ca- sos da Índia e do Brasil. In: VIEIRA, P. F.; WEBER, J. (Orgs.). Gestão de recursos renováveis e desenvolvimento: novos desafios para a pesquisa ambiental. São Paulo: Cortez, 1996. p. 469-494.

. Caminhos para o desenvolvimento sustentável. Rio de Janeiro: Garamond, 2002.

SANTOS, M. A urbanização brasileira. 3. ed. São Paulo: Hucitec, 1996. 157 p.

STEINBERG, M. A (re)construção de mitos sobre a (in)sustentabilidade do (no) espaço urbano. In: ENCONTRO NACIONAL DA ANPUR, 9, 2001, Rio de Janeiro. Anais ... Rio de Janeiro, 2001.

TUDELA, F. Para uma cultura de sustentabilidade urbana. In: ALVA, E. N. Metrópoles (in) sustentáveis. Rio de Janeiro: Relume Dumará, 1997. 137-142 p. 